\title{
Non-conventional renewable energy: comparative analysis of the prospects for the development of energy-economic complex of a state
}

\author{
Yelyzaveta Koniaieva ${ }^{1}$, Oleg Dzoba ${ }^{2}$, Alexey Hostryk $^{3}$, Oksana Lisova $^{4}$, and Dariia Babenko ${ }^{5}$ \\ ${ }^{1}$ V. N. Karazin Kharkiv National University, International Economic Relations Department, Kharkiv, Ukraine \\ ${ }^{2}$ Ivano-Frankivsk National Technical University of Oil and Gas, Institute of Economics and Management, Ivano-Frankivsk, Ukraine \\ ${ }^{3}$ Odessa National Economic University, Department of Cybernetics and Information Technologies, Odessa, Ukraine \\ ${ }^{4}$ Ivano-Frankivsk National Technical University of Oil and Gas, Entrepreneurship and Marketing Department, Ivano-Frankivsk, Ukraine \\ ${ }^{5}$ Simon Kuznets Kharkiv National University of Economics, Department of International Economics and Management of Foreign \\ Economic Activity, Kharkiv, Ukraine
}

\begin{abstract}
The article considers the levels of the energy-economic complex development in the field of nonconventional renewable energy on the example of two countries: Ukraine and Chile; carries out a comparative analysis of growth levels in the share of alternative energy sources in the energy sector of the states. The research determines dynamics and prospects of alternative energy in Ukraine; shows the periods of alternative energy share decreasing and increasing of the countries. Particular attention is paid to the expansion of international relations in the field of scientific and technical cooperation in the field of non-conventional renewable energy between countries. The article indicates and highlights potential solutions to increase the share of non-traditional renewable energy in the Ukrainian energy market.
\end{abstract}

\section{Introduction}

Today in the world there is an acute problem of environmental protection. The world community is moving from the use of traditional sources of electric power to alternative inexhaustible sources. The problem of the correct use of the Ukrainian potential in the field of green energy is relevant today [1]. Effective use of natural potential in the field of non-conventional renewable energy (NCRE) technologies in Ukraine is one of the key issues in the state's energy sector. The priorities of interstate scientific and technical cooperation (STC) influence the economic development of the subjects of the world economy. With the emergence and development of the world economy, STC is constantly expanding and deepening the sphere of its existence, acquiring new forms [2]. However, when implemented, they become relatively independent phenomenon obeying their own laws and have their own specifics in realizing the potential of international economic relations in general. It is one of the active forms of international economic relations (IER), which determines their growing dynamics in modern conditions, is international STC [3], [4]. It has intangible form of economic relations and conditions by the mutually beneficial exchange of scientific and technical knowledge, intellectual property, experience and programs of scientific and technical development, engineering services, etc. All this plays an increasing role in the intensification of scientific production development of the subjects of world economic relations.
On the example of interstate cooperation between Ukraine and Chile, there are approaches to improving the procedure for developing cooperation priorities. The current state of these relations does not reflect real trends in the development of IER in the vector of strengthening the scientific and technical component [5]. The subject of research of the article is formation of scientific and technical cooperation priorities between Ukraine and Chile. The goal is to develop the approaches of foreground IER formation in relation to the conditions in relation to the conditions of Ukraine and corresponding to the needs of overcoming crisis socio-economic phenomena based on the intensification of STC. The objective is to research the dynamics of the actual nonconventional energy production as one of the priority areas of cooperation between Ukraine and Chile.

\section{Materials and methods}

As part of this study, theoretical, methodological and system-logical methods for analyzing primary sources are used, including statistical materials, regulatory documents, scientific publications for descriptive and structural analysis to assess the initial state of international economic relations primary level and methods for forming trends in their development prospects [6].

The comparative approach must be elaborated in terms of its theoretical design and its research strategy on the basis of a goal-oriented point of reference, i.e. what exactly is to be explained [7]. There are five available

\footnotetext{
* Corresponding author: sunnybigday@gmail.com
} 
options: 1. The Single Case Study (either a country, an event or systemic feature); 2. The Single Case Study over time (i.e. a historical study or time series analysis); 3. Two or more cases at a few time intervals (i.e. closed universe of discourse); 4. All cases that are relevant regarding the Research Question under review; 5. All relevant cases across time and space (pooled time series analysis.

Overall, several conditions should be fulfilled before labeling a comparison as mature comparative analysis. First, the purpose of comparison must be explicated early in the project, and it should be a defining component of the research design. Second, the macro-level units of comparison must be clearly delineated, irrespective of how the boundaries are defined. In the contextual environments, specific factors that are assumed to characteristically affect the objects of analysis - be they people, practices, communication products or other structural or cultural elements - must be identified. Third, the objects of analysis should be compared with respect to at least one common, functionally equivalent dimension. Methodologically, an emic (culture-specific) or etic (universal) approach may be applied. Fourth, the objects of an analysis must be compared on the basis of a common theoretical framework and must draw on equivalent conceptualizations and methods rather than be analyzed separately [8]. These elements will be further discussed in the sections that follow.

According to BetterEvaluation, qualitative Comparative Analysis (QCA) is a means of analyzing the causal contribution of different conditions (e.g. aspects of an intervention and the wider context) to an outcome of interest. QCA starts with the documentation of the different configurations of conditions associated with each case of an observed outcome. These are then subject to a minimization procedure that identifies the simplest set of conditions that can account all the observed outcomes, as well as their absence [9]. QCA is a theory driven approach, in that the choice of conditions being examined needs to be driven by a prior theory about what matters. The list of conditions may also be revised in the light of the results of the QCA analysis, if some configurations are still shown as being associated with a mixture of outcomes [10].

\section{Comparative analysis of prospects for the development of energy-economic complex of Ukraine and Chile}

In the conditions of a modern innovative economy, economic relations may have a priority not in commodity items, but in intellectuals and organizational communication systems of their realization. This means the exchange of experience, licenses, know-how, rapid expansion of scientific, technical and technological cooperation [11]. It is through this that it is possible to solve the issues of raising the technological level of various industries and the national economy as a whole, the tasks of its accelerated technological re-equipment, expanding export opportunities and reducing imports, developing technical and economic ties between countries based on specialization and cooperation in the production of various types of products [12].

In our opinion, one of the potential areas is the exchange of experience, knowledge and technologies in the field of the formation and implementation of the strategy for the development of non-conventional renewable energy (NCRE). Prerequisites for this are the following circumstances:

- both in Ukraine and in Chile there are various climatic conditions that imply the development of certain types of NCRE;

- both in Ukraine and in Chile there are sufficient potentials of sources of NCRE;

- both Ukraine and Chile have a comparable research and production potential that can be used to implement the NCRE technologies;

- both Ukraine and Chile, at about the same period, since the 2000s, have embarked on the path of development of the NCRE [13].

However, the growth rate of NCRE in Chile is significantly higher than in Ukraine [14-19], as we presented in Table 1.

Table 1. Dynamics of actual energy production from NCRE (2000-2017) in Ukraine / Chile, GW/h.

\begin{tabular}{|c|c|c|c|c|c|c|c|c|c|c|}
\hline \multirow{2}{*}{$\begin{array}{r}\text { Source } \\
\text { of NRE } \\
2000 \\
\end{array}$} & \multicolumn{2}{|c|}{$\begin{array}{l}\text { Wind } \\
\text { energy }\end{array}$} & \multicolumn{2}{|c|}{$\begin{array}{l}\text { Solar } \\
\text { energy }\end{array}$} & \multicolumn{2}{|c|}{$\begin{array}{c}\text { Biomass } \\
\text { energy }\end{array}$} & \multicolumn{2}{|c|}{$\begin{array}{c}\text { Total } \\
\text { NCRE } \\
\text { produc- } \\
\text { tion } \\
\end{array}$} & \multicolumn{2}{|c|}{$\begin{array}{c}\text { Average } \\
\text { NCRE } \\
\text { produc- } \\
\text { tion } \\
\end{array}$} \\
\hline & 6 & 0 & 0 & 0 & 0 & 941 & 6 & 941 & 2 & 314 \\
\hline 2001 & 16 & 7 & 0 & 0 & 0 & 2068 & 16 & 2075 & 5.3 & 692 \\
\hline 2002 & 22 & 7 & 0 & 0 & 0 & 1944 & 22 & 1951 & 7.3 & 650 \\
\hline 2003 & 31 & 7 & 0 & 0 & 0 & 1807 & 31 & 1814 & 10.3 & 605 \\
\hline 2004 & 33 & 7 & 0 & 0 & 0 & 2031 & 33 & 2038 & \begin{tabular}{|l|}
11 \\
\end{tabular} & 679 \\
\hline 2005 & 38 & 7 & 0 & 0 & 0 & 1790 & 38 & 1797 & 12.6 & 599 \\
\hline 2006 & 35 & 7 & 0 & 0 & 0 & 1431 & 35 & 1438 & 11.6 & 479 \\
\hline 2007 & 45 & 9 & 0 & 0 & 281 & 2696 & 326 & 2705 & 109 & 902 \\
\hline 2008 & 45 & 38 & 0 & 0 & 264 & 3083 & \begin{tabular}{|l|}
309 \\
\end{tabular} & 3121 & 103 & 1040 \\
\hline 2009 & 41 & 79 & 0 & 0 & 139 & 4274 & 180 & 4353 & 60 & 1451 \\
\hline 2010 & 49 & 332 & 1 & 0 & 188 & 2249 & 238 & 2581 & 79.3 & 860 \\
\hline 2011 & 89 & 338 & 30 & 0 & 134 & 4703 & 253 & 5041 & 84.3 & 1680 \\
\hline 2012 & 258 & 409 & 334 & 0 & 134 & 4874 & \begin{tabular}{|l|}
726 \\
\end{tabular} & 5283 & 242 & 1761 \\
\hline 2013 & 637 & 554 & 563 & 8 & 106 & 5761 & 1306 & 6323 & 435 & 2108 \\
\hline 2014 & 1172 & 1443 & 483 & 490 & 169 & 5327 & 1824 & 7260 & 608 & 2420 \\
\hline 2015 & 1084 & 2114 & 475 & 1261 & 199 & 5615 & 1758 & 8990 & 586 & 2996 \\
\hline 2016 & 924 & 491 & 164 & 1029 & 1041 & 5812 & 1579 & 7882 & 526 & 2627 \\
\hline 2017 & 915 & 804 & 190 & 1419 & 2115 & 6124 & 1909 & 9658 & 636 & 2746 \\
\hline $\begin{array}{l}\text { rowth } \\
\text { rate }\end{array}$ & & & & & 0.7 & 6.5 & 119.3 & 8.8 & - & 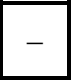 \\
\hline
\end{tabular}

The table shows that in Chile, the growth rate of NCRE generation based on solar, wind energy and bioenergy is much higher than in Ukraine. The Figure 1 illustrates this.

In the process of analysis, the dynamics of average values and trends of total indicators of NCRE production of Chile and Ukraine show the field of growth of potential innovative susceptibility to NCRE technologies in the process of mutual scientific and technical cooperation between the subjects of international economic relations [20], [21]. 


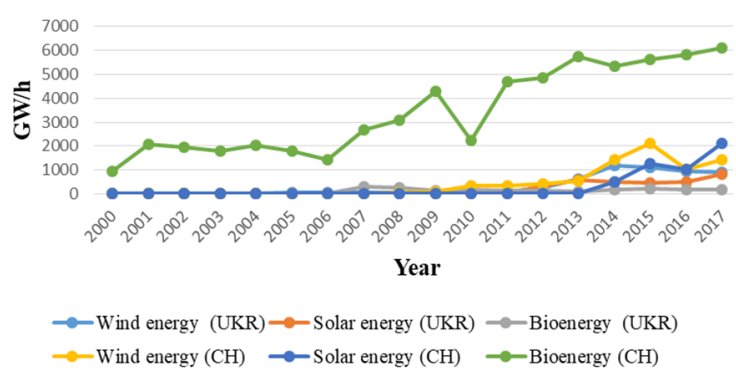

Fig. 1. Comparative dynamics of energy production from various NCRE sources of Chile and Ukraine for 2000-1017.

Justifying the prospects of interstate cooperation between Ukraine and Chile, we made an analysis of the comparative dynamics of the volume of NCRE production. Based on these sources, there are comparative figures for the period from 2000 to 2017. According to Table 1, there are graphs, which presented in Fig. 1, which really reflects the dynamics of these processes. If the starting conditions for the development of NCRE were relatively similar [22], then, as we consider the entire period, we should conclude that the growth rates of various types of renewable energy in Chile significantly exceed Ukrainian ones.

Analyzing the comparative dynamics of trends in NCRE production (Fig. 2), we can conclude that the Chilean dynamics substantially exceed the Ukrainian one, which implies a corresponding analysis of the conditions and forms of state support for these processes. Fig. 2 presents the interpretation of the dynamics of NCRE development based on mathematical methods, in particular the logarithmic smoothing of graphs and their corresponding transformations into averaged trends [23]. This made it possible to visualize graphically the field of potential innovative susceptibility of the development of the use of NCRE technologies by business entities of Ukraine.

This field of innovative susceptibility represents a segment of the innovative information space for the formation of priorities in the interstate scientific and technical cooperation in NCRE field. In particular, on current issues of convergent technologies, it also touches upon the issues of NCRE in terms of using elements of NBIC technologies within its framework. Among them should pay attention to:

1. Whether any party have elements of NBICtechnologies in NCRE field, then this immediately becomes a priority of interstate cooperation.

2. In fact, NCRE technologies already use elements of NBIC technologies. For example, solar collectors have the prospect of nano-coatings. Biotechnologies provide unconventional energy generation technologies from organic waste.

3. A promising direction from the point of view of the NBIC is the creation of energy-saving complexes based on a combination of generating technologies on a traditional and non-traditional basis. This is especially important for improving the efficiency of existing traditional energy generation [24].

For example, it is possible that energy-saving complexes based on, for example, a gas boiler house, will systematically include a solar system and a heat pump, which will allow, as experience shows, to reduce the average annual consumption of fossil fuels by $40 \%$. At the same time, elements of NBIC technologies are used to some extent [25]. All this shows serious scientific production and organizational-economic prerequisites for the formation of the priorities of the scientific and technical cooperation between Ukraine and Chile in NCRE field.

\section{Discussion}

To this end, we propose the following guidelines to define the comparative approach as a distinctive way of analyzing [26]:

1. Describes the core subject of comparative inquiry.

2. Develops a view on which theoretical concepts can 'travel' comparatively as well as measure what is intended (internal validity).

3. Discusses the logic of the comparative method as a means to a goal, rather than as an end in itself.

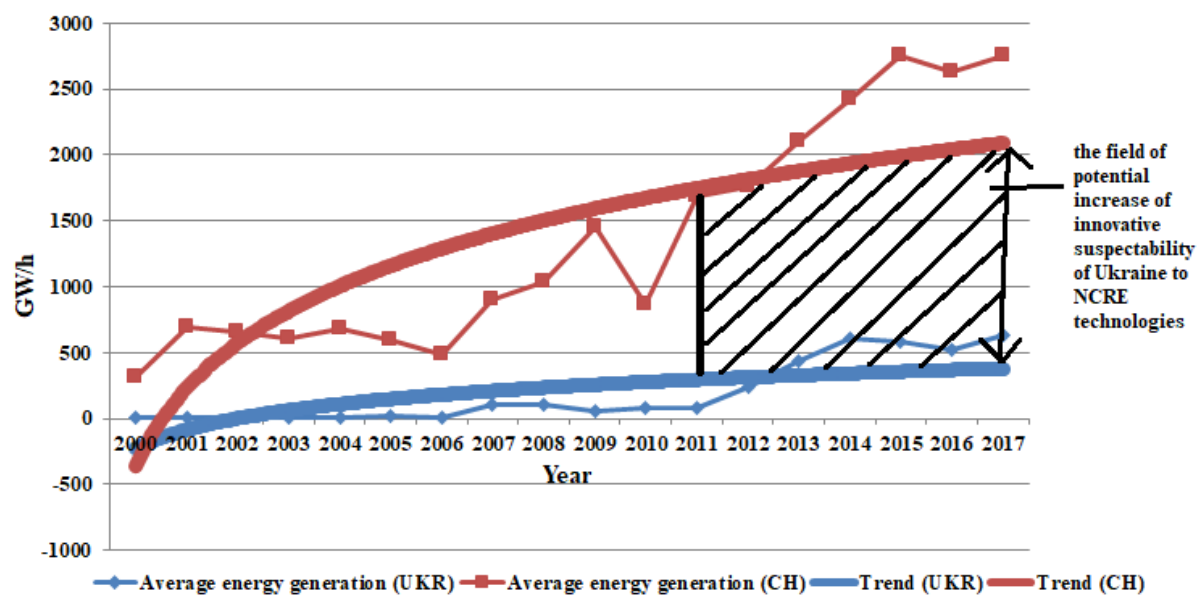

Fig. 2. Dynamics of average values, trends in NCRE production over the years (2000-2017) and the growth prospects of innovative susceptibility to NCRE in the process of the scientific and technical cooperation between Chile and Ukraine. 


\section{Conclusion}

On the basis of a phased analysis of the formation of priorities for the development of Ukraine, we propose an approach for analyzing the integrated development of national economies. According to the authors, this will allow a more reasonable approach to the selection of priorities for intergovernmental cooperation, including relevant areas of development. The results of the analysis made it possible in the framework of interstate cooperation between Ukraine and Chile to identify a promising area for the development of non-traditional renewable energy.

In general, in Ukraine the development of certain areas of NCRE (such as solar and wind power) began within the framework of world trends much earlier than in Chile. However, up to the present, there have been no institutional changes in the attitude towards the NCRE technologies in the country.

In Chile for a relatively short period $2007-2017$, institutional changes have occurred in the sphere of innovation susceptibility to NCRE technologies, which affect a wide range of factors, including political, legal, and socio-economic factors. Separately, it is possible to single out a complex of factors of scientific and technical cooperation with various advanced actors of the world economy on NCRE issue.

Accordingly, within the framework of world development, there is a prospect for the development of the scientific and technical cooperation between Chile and Ukraine on NCRE issues, including:

1. The formation of priorities and the role of state programs of scientific and technical cooperation in the development of national economies.

2. Organizational and economic forms of scientific and technical cooperation in NCRE field between Chile and Ukraine.

3. The experience of state support of subjects of producer-consumer NCRE cycle, taking into account the best international practices.

4. Forms of development of producer and consumer motivation; selection of priorities for NCRE technologies taking into account the experience of advanced economies.

5. Exchange of intellectual products (technology, licenses, know-how, etc.).

\section{References}

1. Ghanbari-Mobarakeh, P., Moradian, M.: A new paradigm for distributed generation management considering the renewable energy uncertainties and demand response resources. IJRER. Int. Jr. of Ren. En. Res. 9(1), 215-225 (2019)

2. Babenko, V., Petuhova, V., Perepelitsia, A.: Forming of informatization strategic prospects for Ukraine in conditions of world economy globalization. Sci. bul. of Polissia. 10, 16 (2017). doi:10.25140/2410-95762017-1-2(10)-24-34
3. Shorikov, A.F., Babenko, V.A.: Optmization of assured result in dynamical model of management of innovation process in the enterprise of agricultural production complex. Economy of Region. 1, 196-202 (2014). doi:10.17059/2014-1-18

4. Sidorov, V., Revyakin, G.: The influence of globalization on the synchronism of development of economic processes within the terms of world economy. Bus. Inf. Jr. 3, 16-20 (2017)

5. RAND Corporation: Objective analysis. Effective solutions: International economic relations. https://www.rand.org/topics/international-economicrelations.html (2019). Accessed 10 March 2019

6. Voynarenko, M., Dykha, M., Mykoliuk, M., Yemchuk, L., Danilkova, A.: Assessment of an enterprise's energy security based on multi-criteria tasks moeling. Int. Res. Jr. 16, 14 (2018). doi:10.21511/ppm.16(4).2018.10

7. Esser, F., Vliegenthart, R.: Comparative research methods. In: Matthes, J., Potter, R. (eds.) Int. Encl. of Com. Res. Mthds., Wiley-Blackwell, London (2016)

8. Marshall, G.: A Dictionary of Sociology. Oxford University Press, Oxford (1998)

9. Rihoux, B., Ragin, C. (ed.): Configurational Comparative Methods: Quality Comprative Analysis (QCA) and Related Techniques. SAGE, London and Thousand Oaks (2008). doi:10.4135/9781452226569

10. Lubetski, V.: Mirovoy rynok tekhnologiy i mesto na nem Rossii. Inov. Sci., 12, 159-163 (2015)

11. Prokopenko, O., Kurbatova, T., Babenko, V., Baldzhy, M., Denysenko, M. (eds.): International economic relations and sustainable development. Drukarnia i Studio Graficzne Omnidium, Chorzów (2017)

12. Babenko, V., Koniaieva, Y.: Prospects for improving technology in non-conventional energy development. V.N. Karazina Nat. Uni. Vestnik. Jr. (2019, in press)

13. Babenko, V., Nazarenko, O., Nazarenko, I., Mandych, O.: Aspects of program control over technological innovations with consideration of risks. Est.-Eur. Jr. 3(4(93)), 6-14 (2018). doi:10.15587/1729-4061.2018.133603

14. State Statistics Service of Ukraine. http://www.ukrstat.gov.ua/ (2019). Accessed 23 March 2019

15. International Renewable Energy Agency. http://www.irena.org (2019). Accessed 23 March 2019

16. Boletín del Mercado Eléctrico: Sector Generación, Diciembre 2017. Generadoras de Chile. http://generadoras.cl/media/pagefiles/377/Boletin_Generacion_Diciembre_20171.pdf (2019). Accessed 23 March 2019

17. Babenko, V. O.: The task of minimax adaptive management of innovative processes at an enterprise with risk assessment. Sci. bul. of Polissia, 1(9), 115121 (2017). doi:10.25140/2410-9576-2017-2-2(10) 
18. Ukraine Sustainable Energy Lending Facility. http://www.uself.com.ua/ (2019). Accessed 25 March 2019

19. Ministerio de Energia, http://www.energia.gob.cl/ (2019). Accessed 25 March 2019

20. Oliinyk, V.: Models of innovative product distribution: global PC sales market. Marketing and Management of Innovations. 4, 15-26 (2017). doi:10.21272/mmi.2017.4-01

21. Wiebe, I., Oliinyk, V., Halynska, Y.: Innovative instrument of collaboration alliance management in the "state-region-enterprise" system of withdrawal of the rent income in the extracting industry. Marketing and Management of Innovations. 2, 247-261 (2018). doi:10.21272/mmi.2018.2-20

22. Deshpande, R.: Analysis of power quality variations in electrical distribution system with renewable energy sources. International Journal of Renewable Energy Research-IJRER. 9(1), 9 (2019)

23. Kvasha, S., Davydenko, N., Pasichnyk, Y., Wasilewaska, T.: Features of socio-economic development of the Baltic states and Ukraine. Bsns. Persp. Jr., 16, 16 (2018). doi:10.30525/22560742/2017-3-5-97-102

24. Babenko, V., Sidorov, V., Koniaieva, Y., Kysliuk, L.: Features and prospects of scientific and technical cooperation in the field of non-conventional renewable energy. Global Jrl. Environ. Sci. Manage. (2019, in press)

25. Jamali, H., Azadi-Ahmadabadi, G., Asadi, S.: Interdisciplinary relations of converging technologies: Nano-Bio-Info-Cogno.

Scientometrics, 116, 22 (2018)

26. Mongeon, P., Paul-Hus, A.: The journal coverage of Web of Science and Scopus: a comparative analysis. Scientometrics, 106, 19 (2016) 